\title{
An Electrochemical Gate Based on a Stimuli-Responsive Membrane Associated with an Electrode Surface
}

Ihor Tokarev, Maxim Orlov, Evgeny Katz, * Sergiy Minko*

Department of Chemistry and Biomolecular Science,

Clarkson University, Potsdam NY 13699-5810, USA

\section{Supporting Information}

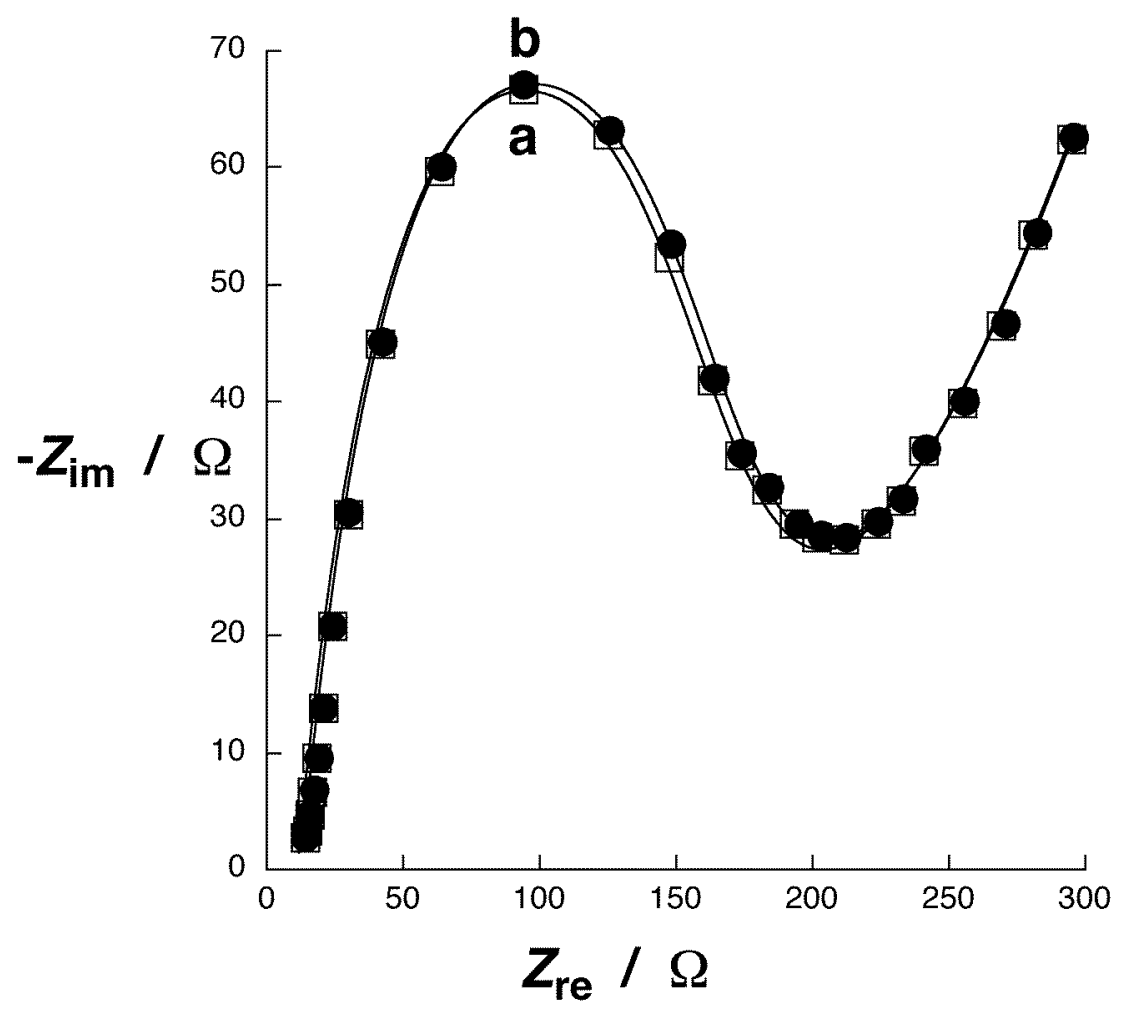

Figure SI-1. Nyquist plots $\left(Z_{\mathrm{im}}\right.$ vs $\left.Z_{\mathrm{re}}\right)$ for the Faradaic impedance measurements performed on the Au electrode modified with the adsorbed P2VP thin film $(0.5 \mathrm{~nm})$ (solid lines correspond to the fit of the experimental points to the theoretical equivalent circuitry): a) in the absence of cholesterol, b) after the electrode soaking in $0.13 \mathrm{M}$ cholesterol solution in chloroform for 5 minutes. The data were recorded in $0.1 \mathrm{M}$ phosphate buffer, $\mathrm{pH}=7.0$, in the presence of $10 \mathrm{mM} \mathrm{K}_{3}\left[\mathrm{Fe}(\mathrm{CN})_{6}\right] / \mathrm{K}_{4}\left[\mathrm{Fe}(\mathrm{CN})_{6}\right]$, 1:1, bias potential of $0.17 \mathrm{~V}$. 


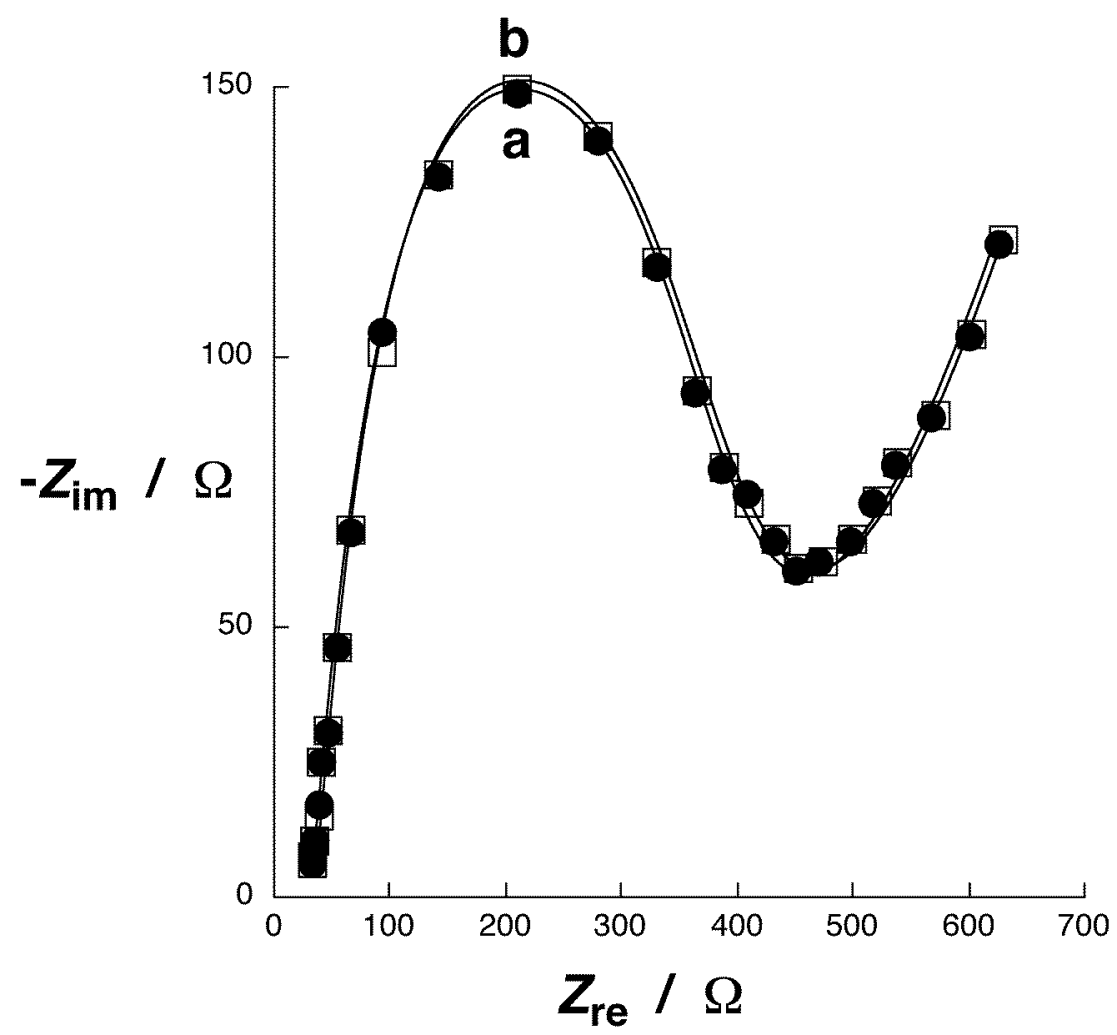

Figure SI-2. Nyquist plots $\left(Z_{\text {im }}\right.$ vs $\left.Z_{\mathrm{re}}\right)$ for the Faradaic impedance measurements performed on the Au electrode modified with the porous-free cross-linked P2VP film (2 nm) demonstrating the $R_{e t}$ value similar to the PGmembrane with the fully open pores (solid lines correspond to the fit of the experimental points to the theoretical equivalent circuitry): a) in the absence of cholesterol, b) after the electrode soaking in $0.13 \mathrm{M}$ cholesterol solution in chloroform for 5 minutes. The data were recorded in $0.1 \mathrm{M}$ phosphate buffer, $\mathrm{pH}=7.0$, in the presence of $10 \mathrm{mM}$ $\mathrm{K}_{3}\left[\mathrm{Fe}(\mathrm{CN})_{6}\right] / \mathrm{K}_{4}\left[\mathrm{Fe}(\mathrm{CN})_{6}\right], 1: 1$, bias potential of $0.17 \mathrm{~V}$. 


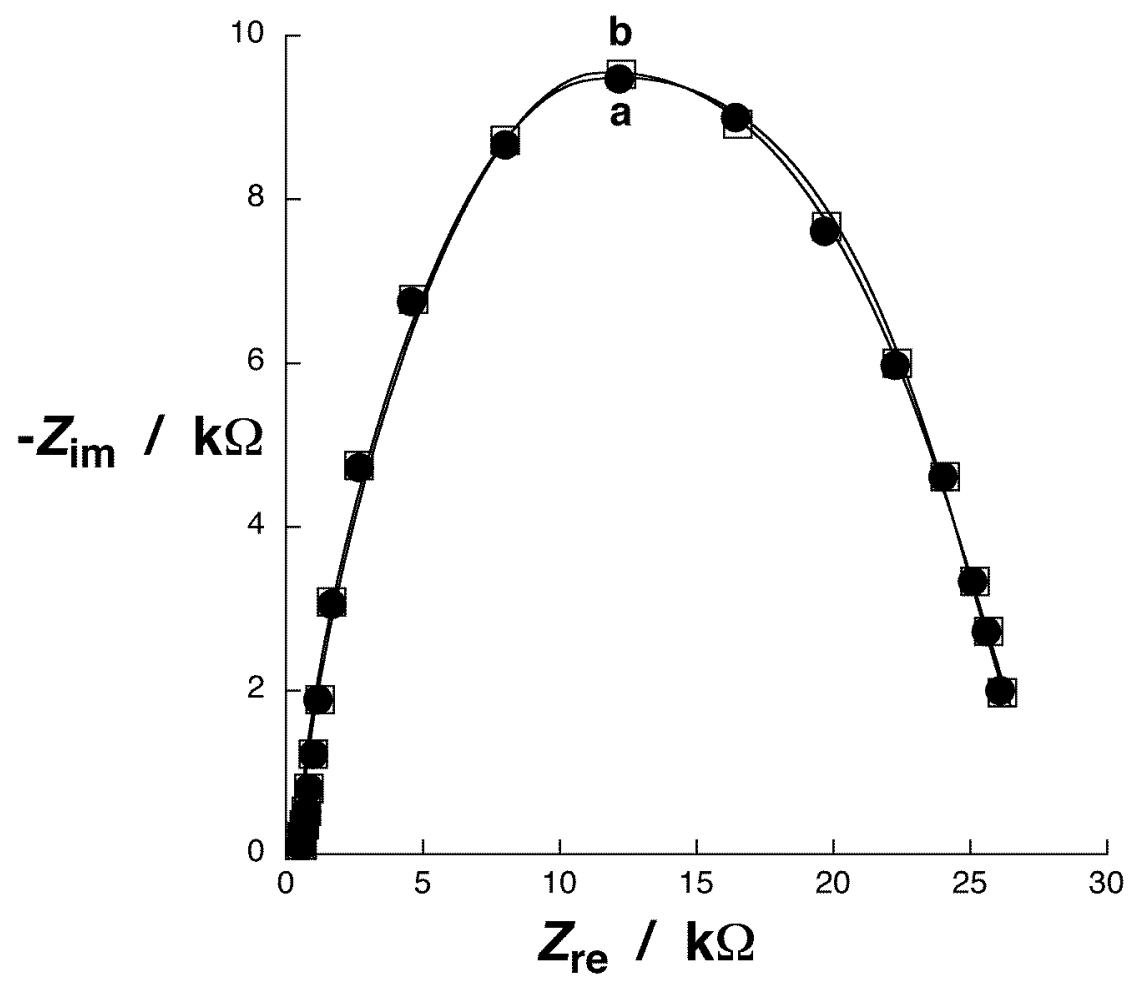

Figure SI-3. Nyquist plots $\left(Z_{\mathrm{im}}\right.$ vs $\left.Z_{\mathrm{re}}\right)$ for the Faradaic impedance measurements performed on the Au electrode modified with the porous-free cross-linked P2VP thick film $(200 \mathrm{~nm}$ ) (solid lines correspond to the fit of the experimental points to the theoretical equivalent circuitry): a) in the absence of cholesterol, b) after the electrode soaking in $0.13 \mathrm{M}$ cholesterol solution in chloroform for 5 minutes. The data were recorded in $0.1 \mathrm{M}$ phosphate buffer, $\mathrm{pH}=7.0$, in the presence of $10 \mathrm{mM}$ $\mathrm{K}_{3}\left[\mathrm{Fe}(\mathrm{CN})_{6}\right] / \mathrm{K}_{4}\left[\mathrm{Fe}(\mathrm{CN})_{6}\right], 1: 1$, bias potential of $0.17 \mathrm{~V}$. 